\title{
Interviews
}

\section{DAM integration for multi-channel publishing - Interview with Mary Yurkovic of Playboy Enterprises, Inc.}

\section{Mary Yurkovic}

With more than 15 years of experience in advertising and publishing, Mary Yurkovic manages Playboy's first corporate digital asset management initiative. Yurkovic is responsible for the implementation and deployment of the Playboy Asset Management (PAM) system. Leveraging her knowledge of color management and digital workflows, she began her career as a graphic designer before becoming an art director. Yurkovic moved into technology when she joined Playboy in 1997. She now draws on all of her varied experience as she creates training tools to migrate users over to the system and document the change management taking place corporation-wide. Prior to Playboy, Yurkovic worked for DDB-Chicago, McKnight/Kurland Design and Consolidated Press, Inc.

Keywords: rights management, print, broadcast, telescope, Playboy, change management

Abstract Four years after Playboy Enterprises, Inc. launched PAM - the Playboy Asset Management system - we speak with Mary Yurkovic, Playboy's DAM Manager. In this article, Mary discusses how Playboy has implemented PAM, integrated PAM with the existing rights asset management system, and supplemented PAM with a top-notch distribution engine to manage workflow for work-in-progress. She also notes the lessons learned in the process by this international multi-channel publishing organization. Journal of Digital Asset Management (2008) 4, 305-312. doi:10.1057/dam.2008.42

MM: We're here with Mary Yurkovic of Playboy Enterprises, Inc.

Mary, please give us a short introduction to you and some of the things you've done in your career.

MY: Sure. I'm the Manager of the Digital Asset Management team at Playboy Enterprises Inc. I've been in various roles with Playboy for more than 10 years. I started off in software support for our graphics technology group, and now I'm in my current role, heading up the corporate initiative for a DAM strategy.

We have a lot of exciting things going on with it, and it is growing at a rapid rate. MM: When you say you started in software support, does that mean you were part of the IT or MIS department?

MY: Yes.

MM: Are you trained as a software engineer? MY: No, my formal background is in graphic design. I've migrated away from the creative group. As computers became more common in the workplace - not that I'm trying to date myself! - I fell into analyzing creative workflows and eventually moved into more of a technical role.

MM: For those of us who may not necessarily have a great familiarity with Playboy, we surely know about the magazine, and perhaps the television offerings. What is the scope of work at Playboy Enterprises, Inc.?

MY: Our flagship, Playboy magazine, is celebrating its 55th anniversary. Our global licensing division, which has been in operation for more than 30 years, extends the Playboy brand to fashion apparel and accessories all over the world. Our entertainment division includes Playboy TV and Playboy Radio, as well as our website, Playboy.com. That's very popular, along with our mobile group. They've really been hot for a couple of years.

MM: And mobile is also a part of your entertainment group?

MY: It is, indeed.

MM: That means that you have a deep library of photographic assets. And I would think a large and rapidly growing library of video and audio/visual content. 
MY:Yes.

MM: The Playboy Rabbit Head logo is such a cultural icon. That probably means that you have many licensing partnerships?

MY: Absolutely. We extend the Playboy brand to domestic and international partners, with more than 150 licensees globally. That includes the partners who publish international editions of Playboy magazine and Playboy websites. We distribute our content to them, as well. We also have agreements to provide content to mobile licensees internationally.

MM: About how many content partners do you think you may have worldwide?

MY: We have more than 50 partnerships with various licensees covering mobile, online and print. MM: Basically, that means that you have many different kinds of people with various kinds of business interests and/or levels of rights and permissions that need to have on-demand self-service access to a variety of digital assets. Is that a fair summarization?

MY: Yes, but to extend upon that - I think a lot of companies and corporations face similar challenges concerning rights managements on the assets they own.

MM: Let's come back to the rights-management issue in a bit. First, I'd like for you to bring us up to date in terms of DAM systems at Playboy today.

As I recall, you deployed your first DAM system several years ago.

Can you take us through some of the thinking that went into that?

MY: Absolutely.

Four years ago, Playboy partnered with North Plains for an asset management solution. We use their TeleScope system, which went live about three years ago. When it launched, we focused primarily on one division, Playboy magazine. A secondary phase focused on Playboy.com, because the website derives some of its content from Playboy magazine.

Because Playboy.com also needs to access content from various other divisions, such as our Special Editions group, we realized we had to get those other groups up and using TeleScope as quickly as possible; so the secondary use for Playboy.com - that part of the workflow could go more quickly.

MM: And is that because the online operation doesn't have to go through the whole production layout - proofing, printing, and distribution cycle?

MY: That's correct. They're also taking a lot of images from our archives, which include more than 15 million iconic images. Those images aren't solely from Playboy magazine. Playboy.com also presents content from our Special Editions group mentioned earlier, which does specialty themed magazines devoted to photography. Playboy.com features a lot of those images, and it's usually fairly straightforward to re-purpose them in reference to rights on those assets.

MM: You were saying that the entertainment group — specifically the dot-com group — was pulling or accessing data from things other than the magazine. Clearly, in the history of Playboy magazine, there would be a photo layout of some Playmate or whatever. For every image that you'd see in the magazine, there would probably be many outtakes. So those outtakes are also part of the archives. Is that right? MY: That is true. Those outtakes can be re-purposed if we have the rights to do so. MM: I imagine that was a major undertaking, just getting the archives into a DAM system. MY: Right.

Just to clarify, we don't have every single piece of film that we've ever created in our DAM system. Our physical archives are just enormous, so that will be an ongoing project for a very long time. .

When we decided to roll out a corporate initiative for a DAM system, our philosophy was to just start from day one and go forward. As requests were made for historical material, those images would be scanned and ingested into the system.

MM: Would you give us a sense of the photo-requisition, scanning and posting process for the repurposing of materials?

MY: A digital photo shoot will take place. There's a post-production process for these images, to retain organization of the images unique file names and all the other little housekeeping chores that need to be done to images so as to keep them organized and accessible for future use.

They're batch-renamed and we make DNGs of them (digital negatives). They're ingested into TeleScope. Our metadata requirements are for image assets to have the photographer's name, model's name (if there's a model in the image), the 
date the image was shot, where the photograph was taken and which group the assets were shot for. These pieces of information are very important to our rights and permissions group.

MM: Tell us a little about the rights information management system.

MY: Our rights-management system is a homegrown system that was built about seven years ago. It keeps track of model information, photographer information and contract-specific information. Just because a photo shoot took place for one purpose in particular doesn't mean that we hold the rights for repurposing it. Usage is dependent upon how the contract for that shoot was written.

For example, if an image was shot for Playboy magazine, it may or may not be legal to reuse it internationally, or online, or in mobile content, but it might be re-purposed for print anytime in any location.

So, some of the contracts - depending on who or what we're shooting - may get very granular.

MM: It would seem to me that each photo shoot would have a set of contracts. That would range from the photographer, the creative director, the model - there might even be branded products that were in the photo.

About how many different contracts, on average, really go into a current photo shoot today?

MY: Again, there are a lot of variables.

The standard contracts we have are for a model, photographer, and the medium of the shoot. Those three contracts are pretty standard for a single shoot. If we do have a product shot in there, we will take the extra steps to obtain information from the company that produced that product.

MM: It would seem to me that other large enterprises where we see a bunch of contracts associated with photos - in many cases, they'll scan the actual contracts. So they have a digitized and dated image of each page of the contract.

Then in some cases, they'll create a deal memo, which is more of a database record. There, you've got alphanumeric text that summarizes the rights and permissions that this contract warrants.

MY: We do something similar to that. The contracts are scanned and ingested into a database. There are also seven or eight people in our rights and permissions group who are very familiar with the content that we have.

Depending on who shoots it, the people in this group know the blanket rights on a lot of this content just from being so familiar with the contracts that have already been written.

MM: Because you're a multimedia publishing organization - specifically where you've got video and audio - and more specifically video that has music in it - and because music tends to get licensed internationally on a country-tocountry basis - can you take us through some of that aspect of multimedia rights?

MY: We have an entire video-operations team in two locations. We have a video team in our Los Angeles office that primarily deals with broadcast video. We have a video-operations team here in Chicago that deals more with our VOD (video-on-demand) content.

Now the VOD I can speak probably more in-depth about, because I'm more familiar with that.

MM:VOD in this context would be the Pay-Per-View channels?

MY: It's more the Internet-subscribed VOD. It's one of our faster-growing areas of the business because it's a newer technology. We have an entire new type of consumer within this group. MM: Let's come back again to lessons learned from your TeleScope DAM system. As you said, initially it was set up to help the magazine publishing group. And as I understand it, Playboy Enterprises Inc. publishes a number of titles.

MY: In addition to Playboy, we have the Special Editions Group that produces 25 "picture book" magazines a year, such as the College Girl or Lingerie series that are mostly composed of photos. The Special Editions have a very quick-turnaround life cycle, and they work closely with our Playboy.com group to re-purpose that material in conjunction with the magazine release.

MM: As well as to merchandise it. Right?

MY: That's correct.

MM: Are there any other magazines that are part of the Playboy portfolio?

MY: We have a catalog magazine group, and we produce content for that, as well. We also produce books that are generally composed of historic photo assets, including more nostalgic 
images and classic photographs. They go into these high-quality coffee-table books.

MM: What other kinds of lessons learned showed up in these last four years? One we've talked about was the rights information and how the mobile and web channels have rapidly expanded the whole rights information management challenge.

MY: Another big lesson that we learned was that, although our DAM system was phenomenal at distributing assets, it was not a good tool for use on work-in-progress for us. To overcome that, we purchased and are implementing a product called Global Edit by Industrial Color. That's helped us to bridge the gap between images coming in from the photographer to the photo editor going through thousands of images, and is making it quicker and easier for the editors to pick the ones they want and get those images to the next stage, whether that is print, online or mobile.

The photo editing process is a visual process. So, you're taking a thousand images and narrowing it down to only ten. You want to pick the best of the best. You want to do this quickly and easily while marking your edits at the exact same time. Global Edit does this very well.

MM: Mary, in that process, one of the things that's happened in this last five or six years has been the shift from film to digital. Now, instead of just shooting five rolls of film with 32 images, we're now talking about 5,000 images or 2,000 images from a photo shoot. Is that about right? MY: Yes. Absolutely.

MM: So then, that creates a huge problem at the beginning called, "I've got these 5,000 images, and in there are 10 that are really good." MY: That's correct. That's where Global Edit really has been a champion - narrowing down a photo shoot and marking those images as selects. In addition, you have the ability to share them with someone wherever that person may be. That has really helped us bridge the gap. MM: Also in the Global Edit system, not only are these editing tools, but each stage of the editing process - because it's fully embraced the XMP metadata model at each stage of the editing process, new metadata can be added to the asset. MY: That's correct. That's very valuable to us. For example, someone within our organization who produced that content may not want another group to reuse an image or an outtake of that image, because they want to reserve the image for use in a calendar or for another book. With Global Edit, they're able to keep the content they need for themselves, and let another group have whatever they don't plan to reuse. All the information saved in XMP from Global Edit is transferable to other programs, such as TeleScope. This helps to streamline the workflow tremendously.

MM: What other kinds of metadata get added in this work-in-process workflow as it's moving through the Global Edit system?

MY: It goes through three photo editors, actually. Photo Editor 3 will winnow down a shoot of 1,000 to maybe 50 and then pass it on to the next person, Photo Editor 2, who will narrow it down maybe to 20 . And then the final photo editor, who's going to pass it off to an art director, will pick the best of the best of those, maybe selecting only five or 10 from a shoot. The final choices are labeled as selects and the rest of the images are labeled as outtakes. The labeling happens automatically and is reflected in the metadata. MM: And at that point, it starts going through the retouch and the digital cosmetics aspects. Right?

MY: That is correct.

MM: That's done in Photoshop or another kind of desktop tool. Is that correct?

MY:Yes.

MM: So then as it goes to a creative director, they prepare it for insertion into the publication. At that point, it gets put into the TeleScope DAM. Is that correct?

MY:Yes, except there are some images that can be put into TeleScope prior to that if we know there's a possibility of a particular shoot being re-purposed internationally.

Also, our Special Editions group works very closely with our Playboy.com group. Their images are usually put into Global Edit right away as low-resolution and then are linked to the high-resolution images stored in TeleScope. This allows other groups immediate access to the images if need be.

MM: It seems that the users accessing assets in the Global Edit system are pretty much part of the core production team prior to its general release. In its general release, you use the TeleScope DAM as the corporate-wide general release distribution mechanism.

MY: That's correct. 
MM: Do you anticipate that eventually Global Edit will subsume or take over the TeleScope function?

MY: I think for right now, the two systems operating separately is fine. We've done a ton of customization to our TeleScope system, and it's working with our rights system. So we would have to take those efforts and put them into Global Edit. That's a possibility, but we're just not there yet. We have other goals and demands for asset management extended to other groups within Playboy.

MM: Why don't we talk about your video asset management initiative at this point.

MY: We have several groups producing still-image content that are also producing video content. For example, when our creative people produce a photo shoot, they also shoot a behind-the-scenes video of the model doing her makeup and hair, as well as an interview with her.

Those video assets are valuable to Playboy, so all of the areas that produce and use video footage are investigating the best ways to store it and make it available for re-purposing.

It is a huge undertaking, and we want to make sure we invest in a product that fits our needs and our company.

MM: Mary, why don't you give us a sense of the video playout or distribution channels that are currently part of Playboy Enterprises?

MY: Some of the current channels are broadcast video and IS VOD - Internet-subscribed VOD.

We have systems in our Los Angeles office, which distribute broadcast video, and in Chicago, we have Internet-subscribed VOD.

MM: Clearly you have broadcast as a distribution outlet. It would seem to me that you have DVD as another publishing outlet for video, and then you have VOD.

MY: Yes, our Internet-subscribed VOD. That's one of our newer outlets that we're focusing a lot of attention on, as well - to get that content out to the Internet and to the customer as quickly as possible.

MM: Yes. Then another playout scenario might be a mobile device?

MY: Yes, they can take clips of videos and cut them down to a manageable mobile format. The various video groups always share their content with the mobile group, so the mobile group could take those clips and fulfill licensing agreements.
MM: Do you do any podcasting?

MY: Online, we do.

MM: Then you also have video that's served at Playboy.com or whatever. You probably also have video footage that's played at your clubs. Right?

MY: Currently, we only have one Playboy Club, at the Palms Casino Resort in Las Vegas. There are 60 plasma screens at the Club, but they display a montage of still images, not video. MM: Is there also - using video where you're adding advertisements either pre-roll or post-roll? Or is it just purely, "Here's the Playboy brand material?"

MY: It's purely Playboy brand material, unless we've partnered with someone to produce that particular shoot. For example, if a partner such as Captain Morgan co-sponsors an event with us, such as a Super Bowl party, then we'll share content that extends both of the brands.

MM: Sure.

As you have started to think through the business and operational requirements for transitioning your video from linear programming with content on tape or DVD into a digital asset management system for video, what were some of the other things that you've begun to take into consideration?

MY: Archiving video requires a huge amount of storage space. We also have to consider whether to store raw footage or every cut version of it. We never know where markets are going to peak, or what may happen in terms of world events. We need to be able to find the footage we need as quickly as possible, especially when we receive short-deadline requests from the news media.

MM: That would be another distribution point - publicity.

If I understand you right, one of the business criteria that you wanted to satisfy was the ability to quickly locate and pull out material in minutes or hours, based on some current event. MY: Correct.

MM: What other business requirements were you trying to satisfy here, in terms of your video operations DAM?

MY:You never know what the future's going to hold, as far as technology is concerned. But we know we want to have our video content in a place where it can be digitized more quickly or where it can move to the next level of technology if we need it to do that. That's where the success to the mobile group was 
proven - with our ability to move on that quickly, extending the brand.

MM: Can you take us through the workflow steps? What sort of video ingest tools do you use? MY: Currently, because video is produced in several locations, there are different workflow steps due to the different mediums produced and what it is being used for.

MM: What other sorts of things are you trying to achieve with this video DAM? For example, some video DAMs are really more about being a repository for the purpose of facilitating distribution. Kind of like what you're doing with the TeleScope DAM for images.

Some video DAMs are more production management hubs. Kind of like what you're doing with Global Edit. Is there a sense of which of those two emphases you anticipate in the video DAM? Or do you want to do them both? MY: We want to do them both. But realistically, we know that distribution — speed to market - is important to us.

MM: Currently, are you using the TeleScope DAM for any video content?

MY: We are not. We are only using it for image assets. We would eventually like to utilize TeleScope for document assets in the near future, though.

MM: That then brings up another set of requirements. For example, one approach would be to simply take your magazines and books and to essentially move a PDF of them into an asset repository. Some of the more advanced DAMs will allow you to get individual page views of a multipage PDF document, so that you can actually tag individual pages. Right?

MY: Right.

MM: Another approach would be to take the published work and take it through what I'm calling a "content refinery" process. It basically digests the formatted document, and then creates what we're now calling "intelligent content subassemblies."

MY: Right.

MM: Those are all basically independently XMLtagged content that include not only the text but also the formatting, so that we can quickly reflow those subassemblies into new formats - be they online or mobile or whatever.

MY: Sure.

MM: That then gets into a whole content repository and a processing system for that. Is that the direction that Playboy's headed?
MY: Yes, that is the direction Playboy is headed. It's our goal to have content in an asset management system that's keyword searchable. If you're looking for an article on baseball, you may come across several articles, just by key searching. That's tremendously valuable for us as we repurpose content to other distribution channels that may exist.

Earlier, I had mentioned some of the other books that we publish, such as Hef's Little Black Book, that contain classic images. There is a tremendous opportunity to partner with newspapers, magazines and other outlets, if we can provide the capability for them to receive our content as they need it, provided the rights are cleared for it.

MM: One of the things that we've been tracking has been this digital value chain for publishing operations.

Working backward from the consumer, the first domain is what I call "brand space." Brand space is the socialized dimension of the Internet.

We all hear about the extreme multitasking of today's younger consumers. But

fundamentally, the technology as it addresses the brand space is really search optimization, keyword buys and similar things.

The next phase moves deeper into the organization. It's what we're now calling an engagement theatre. An engagement theatre is where that self-directed consumer first starts to engage with the brand and the content.

So, things like "user experience," navigation, search - faceted or multimodal search, becomes really important.

Another aspect of the engagement theatre is the core concept that we're calling, "Contextual consumption." As I visit Playboy.com, it creates a context of content and advertising around who I am as a visitor, or how I'm beginning to interact with the content.

That is really the job of the Content Management System (CMS).

Then as we move deeper into the organization, we run into what we call the content optimization group. At the heart of the content optimization group, we find text-mining engines. They can take an entire archive of material and really create content consumption contexts.

That's where the contextual advertising really gets made. Where it's said, "Okay. Here are all 
the articles related to Barry Bonds Baseball," and here is what advertising would be suitable to serve up to somebody with those interests. Including interviews with Barry Bonds that were done in a Playboy interview six years ago.

Then as we go deeper into the organization, we find a content refinery, where we've taken the Quark or InDesign or PDF pages and RIPd them apart into intelligent subassemblies. That's kind of an ingest-processing-refining process, where everything lives as an XML repository.

In that XML repository, we also have all the images that are a part of that. That's all tagged, as well. But it's tagged in a way for automated publishing or just-in-time, just-for-me output.

Be it print or online.

Then as we go deeper into the organization, we find then the editorial operations, where you've got the photo desk and the writers and all of the editorial systems that are a part of that.

Then as we go to the very front end of the editorial system, many of the magazines and publishers today are now dealing with social media operations. Specifically, user-generated content and how user-generated content - be it text, blog, posts, letters to the editor, as well as user-generated videos and user-generated photos - become part of the overall conversation around the brand.

Admittedly, a lot of that's not necessarily suitable for a high-fidelity high-production value magazine like Playboy. But it has great relevance and meaning for the online operations.

MY: Right.

MM: So we go through that digital value chain from a social media operations to an editorial operations, to a content refinery to content optimization, to the engagement theatre and then eventually to the brand space. It sounds like what you're doing, Mary, is creating systems for each of those phases.

MY: For some of it, we are. We use MEI's K4 Solution for publishing Playboy magazine. That works well. Other groups may use a homegrown system for their particular content or workflow process to get the brand of their medium to market. It's our goal in the future to have these systems connect to our asset management system, for a more streamlined workflow. MM: In the editorial operations, which now ultimately mean a multi-channel online-offline editorial operation, do you have a lot of editorial content for online that does not move through your K4 editorial system?

MY:Yes, we do. Our Special Editions magazines do not go through our K4 system. Neither do the catalog nor on-line groups. They have different workflow systems in place for their editorial processes.

MM: For the most part, it probably starts off as a Microsoft Word document or some other sort of word processing document.

MY: Yes.

MM: Then it probably goes into some sort of web content-management system pretty quickly. MY: That's correct.

MM: Which web-content-management system do you guys use?

MY: We have a homegrown system that we're using here, currently.

MM: That includes all of the workflow for editorial that goes into the web content management?

MY: For online, yes. That is correct.

MM: So as we are beginning to look at the next phase of that - which is the content refinery - specifically, the creating of XML objects - what do you have in place now or what are you considering in that respect?

MY: As far as getting that content into the asset management system?

MM: Yes. Editorial as an asset. That's right. MY:Yes. PDF.You mentioned PDFs being RIPd apart. That adds value to them. They're being put into the asset management system, allowing them to be keyword-searchable within that system.

MM: Great.

That's a pretty good profile, in terms of what's going at Playboy Enterprises. So as you're beginning to really look at the whole video operations with more of an emphasis on distribution - because time-to-market is more of a business driver than, say, workflow automation of the video operations, have you yet developed a short list of vendors that you're looking at there, yet?

MY: We have developed a short list of vendors. We're working really closely with our West Coast office, which is taking the lead on their portion of what the requirements are.

MM: Absolutely. I look forward to touching base with you in another six months or a year to find out what shook out on your video DAM. 
MY: Good!

MM: As we start to summarize our interview here today, were there any particular aspects of the journey of DAM in Playboy Enterprises that you'd like to share at this point?

MY: I think with any organization, you've got to plan. You have to rethink things. You have to make sure you talk to everybody in the group before you roll out your asset management system. You want to make sure your system is flexible enough to be altered to accommodate change.

MM: To what extent did an independent consultant play a role in guiding you through some of these otherwise thickets of information and confusing things?

MY: It's always great to have someone from the outside, with no preconceived notions of how things have always been done, to come in and observe what's going on and see things that perhaps a person on the inside may have missed. There's tremendous value with that.

When we were rolling out our DAMs, we used North Plains as an independent consultant. MM: With respect to the development of the initial metadata schema for the TeleScope and/or for the Global Edit system, did you engage any kind of independent metadata consulting practices? Or was that simply something that you did internally?

MY: We handled it internally.

MM: Fabulous.

MY: We migrated from that homegrown asset management system, and have added to it to support some distribution points for various groups. And it seems to work.

MM: That actually goes to another kind of best practice. That is, to start with a small tightly focused prototype, where you really develop the metadata schema in terms of how various groups categorize, and therefore want to retrieve assets by.

While it may be humble in terms of scope and in terms of the number of assets or number of users, it nonetheless becomes the seed that begins to grow into a whole enterprise DAM.
MY: Absolutely. Having that pilot group is so important. It will really gauge acceptability within the users. All eyes are on this particular project - who was making a success of it and how they were using it and where we can tweak the system. So it's always going for that little test-pilot group and picking the lowesthanging fruit off the ground.

MM: It also helped that your CEO was very public. I think she had an interview in The Wall Street Journal — or some prominent magazine - about the DAM initiative.

MY: Yes.

MM: So you had a mandate from heaven to make it so.

MY: Yes, because Christie Hefner saw the tremendous value in it, as well.

That's what happened with the little homegrown system. She saw how quick and easy it was for people to get content from Point A to distribution. Right there is your change champion. The next step is to put this in place for all of our content, because the media we use to entertain ourselves have changed significantly. MM: It all got optimized for presenting to a non-technical executive who's really at the level of organizational strategy, and having him or her really get the power of this, so it becomes almost a self-evident value proposition - as opposed to a long technical explanation.

MY: Yes, making something visually easy can be a great selling point.

MM: When I did an interview with the Martha Stewart Living Omnimedia Group, exactly the same thing happened to Martha Stewart. She saw the production prototype of DAM, and already began to conceive how she could create new products almost on-demand. Martha Stewart is all about creating new Martha products. Of course, that led into a very large and ultimately very successful DAM system. MY: Absolutely.

MM: Mary, I want to thank you so much for sharing with us today.

MY: Great. Thank you, Michael, for inviting me. 